\title{
Statistical characterisation of intact rock properties at a Canadian underground mining project
}

\author{
M Grenon Laval University, Canada \\ C Boudreau Laval University, Canada \\ G Bruneau Laval University, Canada \\ R Caumartin Glencore Raglan Mine, Canada
}

\begin{abstract}
At the early stages of an underground mining project in the Canadian arctic, two successive field and laboratory campaigns were undertaken to evaluate intact rock properties (tensile strength and uniaxial compressive strength (UCS). All tests were performed according to the International Society for Rock Mechanics (ISRM) suggested methods. Intact rock properties were evaluated for several rock types. The obtained results were compared to target levels of confidence associated with different stages of a mining project. This was done using various statistical analysis methods. The results obtained for the different rock types are presented and discussed. A discussion is also provided on the level of confidence required for permanent versus temporary openings at underground mines. The approach can also be used as a tool to identify geotechnical drilling targets for subsequent characterisation campaigns.
\end{abstract}

\section{Introduction}

The design of underground mining excavations relies on rock mass geotechnical characterisation. For laboratory tests on intact rock specimens, the guidelines of the ISRM (Brown 1981) are commonly followed. The ISRM suggests testing procedures and a minimum number of specimens to be tested for a given type of strength test.

On the other hand, the development of an underground mine is a complex process and the level of knowledge on rock mass properties should arguably improve along the way. Read and Stacey (2009), for example, suggest that a mining project should be divided in five major steps: conception, pre-feasibility, feasibility, construction and operation. Accordingly, they suggested target levels (Table 1) of data confidence that is required for each of these steps for all important aspects of a geotechnical model. These confidence levels were developed by a sub-committee of the CSIRO project on large open pit mines (LOP).

Based on the results of laboratory tests on intact rock for a mining project, the objectives of this paper are, firstly, to quantify the variability of the obtained results for both tensile strength $\left(\sigma_{t}\right)$ and UCS for the project, and secondly, to propose a methodology to link variability in the results to the target levels of data confidence proposed by Read and Stacey (2009) for rock mass properties. It is suggested that these statistical analyses will improve the understanding of intact rock properties (at the mining project) and allow optimisation of future test programs while maximising representativity of the results. Finally, the methodology will allow for improved identification of future target zones for intact rock strength characterisation.

\section{$1.1 \quad$ Case study}

Raglan Mine, a Glencore company, is located at the northern tip of the Ungava (Nunavik) Peninsula in Quebec, Canada, north of the 55th parallel and approximately 1,800 kilometres north of the City of Montreal (Figures 1 and 2). The 70 kilometre-long property consists of a series of high-grade sulphide deposits composed of nickel, copper and PGE. The climate is semi-desert arctic in a region of permafrost 
(mean depth of about $585 \mathrm{~m}$ ). The climate is severe in both wind and temperature conditions, where the average yearly temperature is $-10^{\circ} \mathrm{C}$ and temperatures in winter are regularly below $-30^{\circ} \mathrm{C}$.

Table 1 Suggested levels of geotechnical effort and target levels of data confidence by project stage (Read 2013)

\begin{tabular}{lccccc}
\hline $\begin{array}{l}\text { Project level } \\
\text { status }\end{array}$ & Conceptual & Pre-feasibility & Feasibility & $\begin{array}{c}\text { Design and } \\
\text { construction }\end{array}$ & Operation \\
\hline $\begin{array}{l}\text { Geotechnical } \\
\text { level status }\end{array}$ & Level 1 & Level 2 & Level 3 & Level 4 & Level 5 \\
\hline $\begin{array}{l}\text { Geotechnical } \\
\text { characterisation }\end{array}$ & $\begin{array}{c}\text { Pertinent } \\
\text { regional } \\
\text { information }\end{array}$ & $\begin{array}{c}\text { Assessment and } \\
\text { compilation of } \\
\text { initial mine scale } \\
\text { geotechnical } \\
\text { data }\end{array}$ & $\begin{array}{c}\text { Ongoing } \\
\text { assessment and } \\
\text { compilation of all } \\
\text { new mine scale } \\
\text { geotechnical data }\end{array}$ & $\begin{array}{c}\text { Refinement of } \\
\text { geotechnical } \\
\text { database and } \\
\text { 3D model }\end{array}$ & $\begin{array}{c}\text { Ongoing } \\
\text { maintenance } \\
\text { of geotechnical } \\
\text { database and } \\
\text { 3D model }\end{array}$ \\
\hline Geology & $>50$ & Target levels of data confidence (TLDC) (\%) & $>$ 80-90 \\
Structural & $>20$ & $50-70$ & $65-85$ & $>75$ \\
Hydrogeological & $>20$ & $40-50$ & $45-70$ & $60-75$ & $>75$ \\
Rock mass & $>30$ & $30-50$ & $40-65$ & $60-75$ & $>80$ \\
Geotechnical & $>30$ & $40-65$ & $60-75$ & $70-80$ & $>80$ \\
\hline
\end{tabular}

The current mine production is provided by four underground mines: Katinniq, Mine 2, Kikialik and Qakimajurq. The ore extracted from these mines is crushed, ground and processed on site to produce a $\mathrm{Ni}-\mathrm{Cu}$-PGE concentrate. Approximately 1.3 million tonnes of ore are treated yearly at the concentrator. Ore zones are typically found in intrusive/extrusive mafic-ultramafic rocks. The host rock lies on gabbro rocks (footwall), while the hanging wall is composed of volcanic rocks. It is also possible to find argillaceous sediments interlayed in the vicinity of the mineralised zones. In the present paper, the mafic-ultramafic rock types analysed are olivine pyroxenite (OP), ore zone (OZ) and peridotite (PE), while the gabbro rock types are normal gabbro (NG) and leucogabbro (L). Volcanic rocks mainly consist of agglomerate breccia $(A B)$, while the sedimentary rocks are identified as argilite (AR) and hornfelsed (HS).

In order to extend the life of Raglan Mine, the Phase II project aims to develop two new mines, Mining Project 14 and Mining Project Donaldson (see Figure 3). From actual knowledge of the project, the rock mass is comparable to the conditions seen in Raglan's other underground operations. However, some ore lenses are larger and deeper, which may indicate different rock mass properties. Furthermore, deeper lenses suggest a potential exists for mining below the permafrost limit, which will possibly have an impact on the mining method.

For this study, the geotechnical data comes from two new mining projects as part of Phase II studies. Two field campaigns took place at these projects, one in 2014 (scoping level) and one in 2015 (pre-feasibility level). The nomenclature used for those campaigns is based on Glencore Raglan's naming convention.

For the first field campaign (2014), Mining Project Donaldson's samples came from two diamond drill holes (DDH) drilled from the surface that reached a depth of 126 and $351 \mathrm{~m}$. Mining Project 14 samples came from one DDH targeting an ore zone at approximately $250 \mathrm{~m}$ below the surface. At the scoping level, the goal of the field campaign was to validate that the rock mass is similar to that in the other mining areas of the property. In Mining Project 14, specimens were selected in the same vicinity (single hole) but at various depths. 


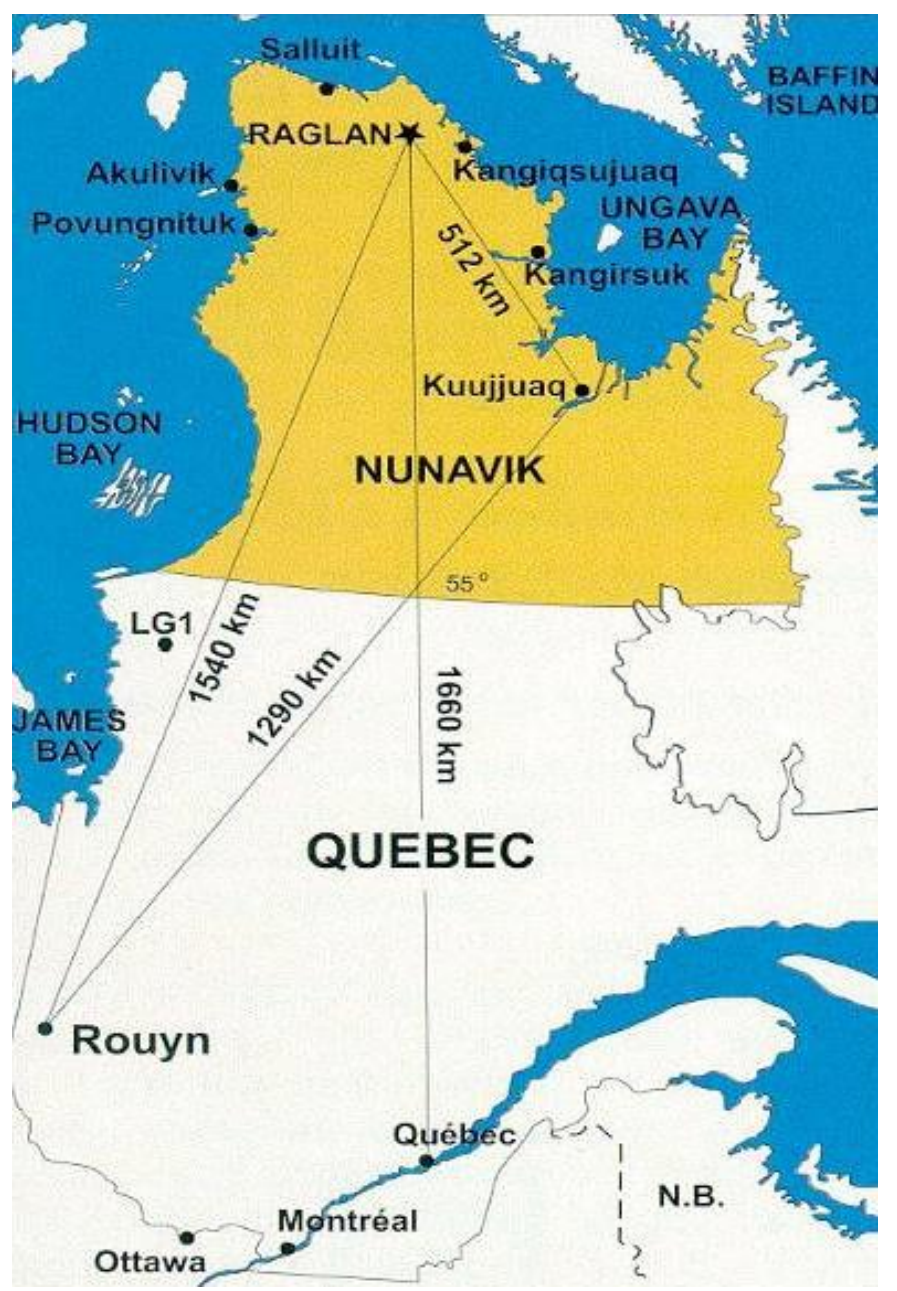

Figure 1 Site location

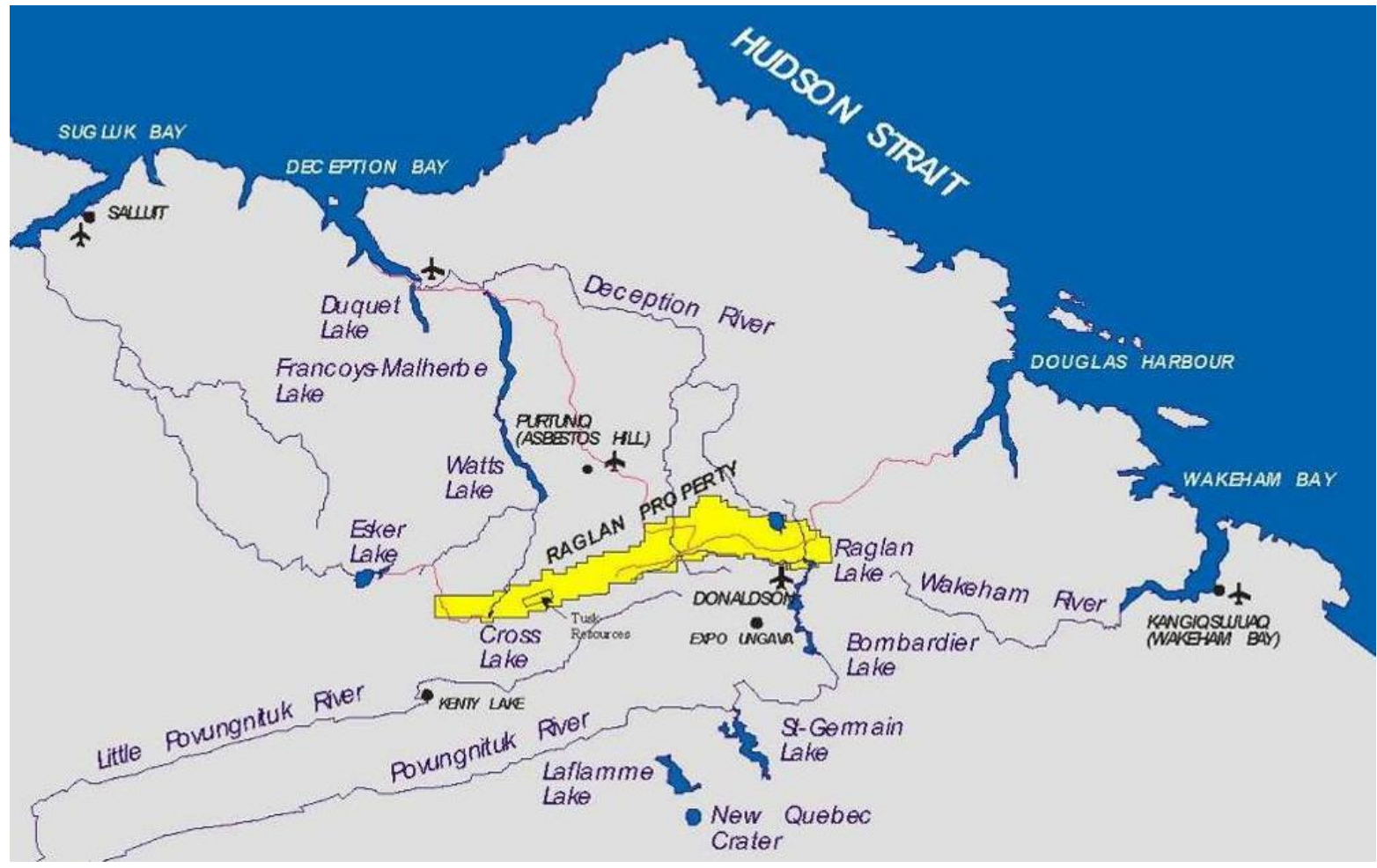

Figure 2 Raglan Mine property 


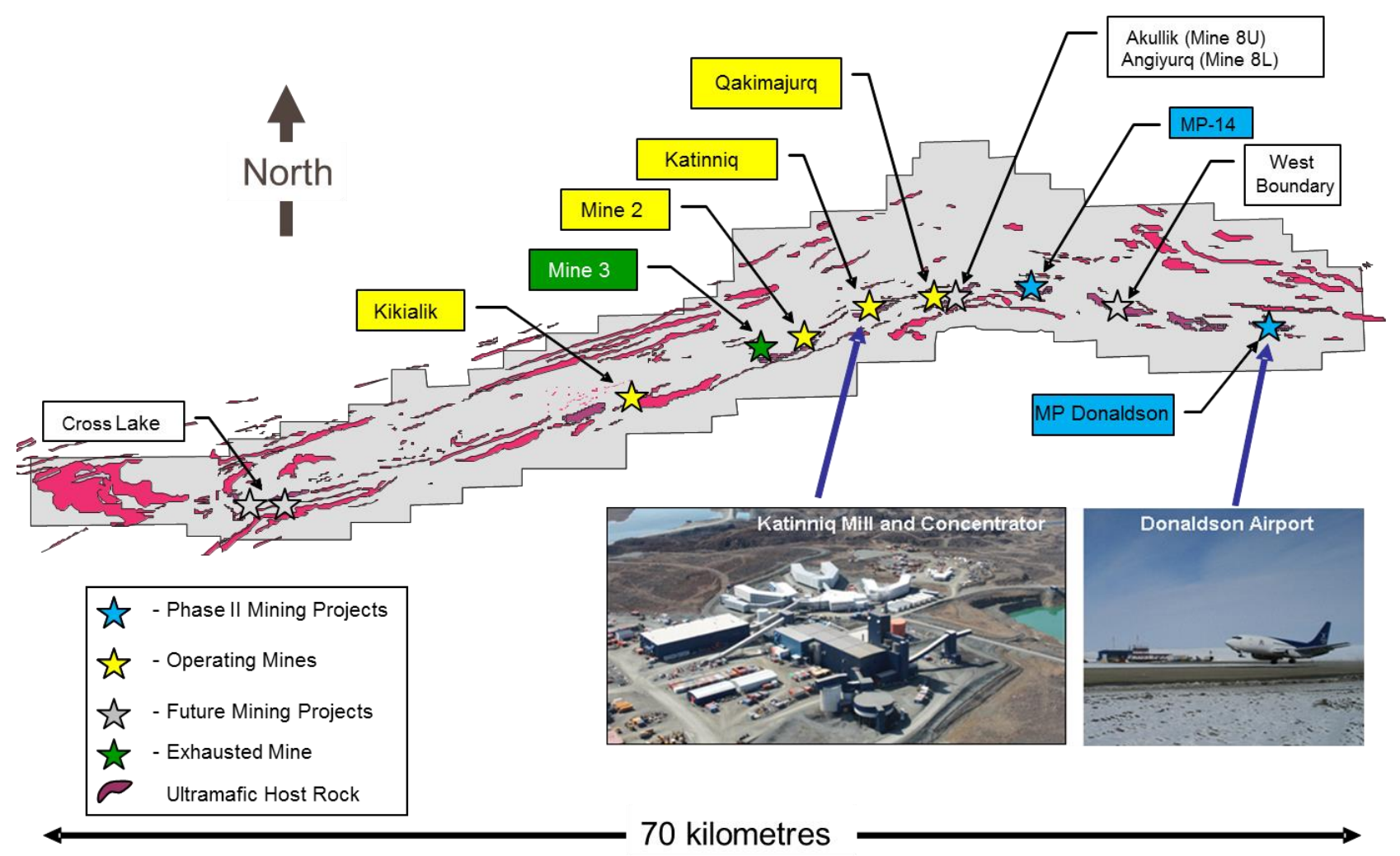

Figure 3 Raglan Mine operations and developing projects

The second sampling campaign (2015) was part of an orebody delineation drilling program in the two zones. Mining Project Donaldson's samples came from nine DDH drilled from the surface targeting each of the known ore lenses (depth ranging between 80 and $415 \mathrm{~m}$ ). The Mining Project 14 samples came from four DDH all targeting one of the biggest ore zones at approximately $480 \mathrm{~m}$ below the surface. Furthermore, some historic geological holes were extended to $750 \mathrm{~m}$ depth. At the pre-feasibility level, the purpose of the field campaign was to increase the number of test samples, but also to improve representation of the material properties within the rock mass.

In this paper, the cores were sampled and tested to investigate two intact rock properties: $\sigma_{t}$ and UCS, according to the ISRM guidelines. The tests were performed at two different accredited facilities. Table 2 summarises the information for the two campaigns at both sites. Four rock types were characterised for Mining Project Donaldson and four others at Mining Project 14. 
Table 2 Number of specimens used for strength testing

\begin{tabular}{cccccccc}
\hline Mining & Rock type & \multicolumn{3}{c}{ Number of specimens $\left(\sigma_{\mathrm{t}}\right)$} & \multicolumn{3}{c}{ Number of specimens (UCS) } \\
project & & $\mathbf{2 0 1 4}$ & $\mathbf{2 0 1 5}$ & $\mathbf{2 0 1 4 - 1 5}$ & $\mathbf{2 0 1 4}$ & $\mathbf{2 0 1 5}$ & $\mathbf{2 0 1 4 - 1 5}$ \\
\hline Donaldson & OP & 5 & 12 & 17 & 5 & 6 & 11 \\
& NG/L & 5 & 5 & 10 & 10 & 6 & 16 \\
& AR/HS & 6 & 6 & 12 & 21 & 3 & 24 \\
& AB & 4 & 4 & 8 & 5 & 3 & 8 \\
\hline \multirow{2}{*}{$\mathbf{4}$} & OP & 7 & 8 & 15 & 7 & 4 & 11 \\
& OP-OZ & 2 & 2 & 4 & 3 & 1 & 4 \\
& NG/L & 7 & 17 & 24 & 10 & 17 & 27 \\
& PE & 7 & 5 & 12 & 15 & 7 & 22 \\
\hline
\end{tabular}

\section{Quantifying variability in the results using the small-sampling theory}

For a geotechnical laboratory testing program on intact rock samples, 40 tests are rarely performed on a given rock type due to cost constraints. The small sample method relies on the notion of statistical inference to quantify the variability of the results for a small sample $(n<40)$. Variability of the sample is quantified using the relative error on the distribution mean. This approach is widely accepted in statistics and is now used in rock engineering applications (Gill et al. 2003; 2005; Fillion \& Hadjigeorgiou 2013).

\subsection{Confidence interval on the distribution mean}

According to the small-sampling theory, if $\bar{X}$ and $s$ are the mean and the standard deviation of a random sample from a normal distribution with unknown variance, a 100(1- $\alpha) \%$ confidence interval on the distribution mean $(\mu)$ is given by Equation 1 (Montgomery \& Runger 2011):

$$
\overline{\mathrm{X}}-\mathrm{t}_{\alpha / 2, \mathrm{v}} \frac{\mathrm{s}}{\sqrt{\mathrm{n}}} \leq \mu \leq \overline{\mathrm{X}}+\mathrm{t}_{\alpha / 2, \mathrm{v}} \frac{\mathrm{s}}{\sqrt{\mathrm{n}}}
$$

where:

$$
\begin{aligned}
\mathrm{n}= & \text { number of specimens in the sample. } \\
\mathrm{t} \alpha / 2, \mathrm{v}= & \text { the confidence coefficient obtained from the student } \mathrm{t} \text { distribution for a two-sided } \\
& \text { confidence with } \mathrm{n}-1 \text { degrees of freedom. }
\end{aligned}
$$

\subsection{Relative error of the distribution mean}

The length of a confidence interval is a measure of an estimation's precision. For a given sample, the maximum absolute error $\left(E_{a}\right)$ on the determination of the distribution mean $(\mu)$ is the half length of the confidence interval of a $100(1-\alpha) \%$ confidence level (Montgomery \& Runger 2011):

$$
E_{a}=\frac{\left(\bar{x}+t_{\alpha / 2, v} \frac{s}{\sqrt{n}}\right)-\left(\bar{x}-t_{\alpha / 2, v} \frac{s}{\sqrt{n}}\right)}{2}
$$

When the equation is simplified, the maximum absolute error $\left(E_{a}\right)$ becomes:

$$
E_{a}=t_{\alpha / 2, v} \frac{s}{\sqrt{n}}
$$

The maximum relative error $\left(E_{r}\right)$ is obtained by dividing the maximum absolute error $\left(E_{a}\right)$ by the sample mean:

$$
E_{r}=\frac{t_{\alpha / 2, v} \frac{s}{\sqrt{n}}}{\bar{X}}
$$


The student $\mathrm{t}$ coefficient $t_{(\alpha / 2, v)}$ is obtained for a $95 \%(\alpha=0.05)$ confidence interval on the distribution mean $(\mu)$ as suggested by Gill et al. (2003).

\section{Defining the target levels of data confidence and the geotechnical level}

Target levels of data confidence (TLDC), expressed in percentages, have been proposed by Read and Stacey (2009) for every aspect of the geotechnical model (Table 1). To maintain consistency with guidelines used to report the level of confidence towards mining exploration works, the geotechnical levels and the TLDC were defined to correspond to the structure of the Joint Ore Reserves Committee (JORC) Australian code (Joint Ore Reserves Committee 2004) describing the mineral resources. According to Read and Stacey (2009), there is anecdotal evidence that the mining industry would be using a target level of confidence of $\pm 25 \%$ for indicated mineral resources and \pm 10 to $\pm 15 \%$ for measured mineral resources. These numbers are compatible with target levels 2-3-4 presented in Table 1 for the geology aspect of the geotechnical model. In this paper, these ranges are interpreted as the maximal relative error $\left(E_{r}\right)$ of the mean of an evaluated property.

\subsection{Linking the target levels of data confidence and the relative maximal error}

This paper proposes linking the results of the small sampling method to the target levels of data confidence using the relative maximal error $(E r)$ on the distribution mean of an investigated geotechnical property using Equation 5:

$$
\operatorname{TDLC}(\%)=100-100 E_{r}
$$

In the analysis of the results for a given sample, the maximal relative error $\left(E_{r}\right)$ is computed for a confidence interval of $95 \%(\alpha=0.05)$. Equation 5 can be used to evaluate the level of data confidence and thus determine the geotechnical level of the investigated property. Accordingly, a large confidence interval can be accepted at the early stages of a mining project. This interval should reduce as the project advances towards construction and operation.

Table 3 TLDC for underground mining excavations for rock mass properties

\begin{tabular}{lcccccc}
\hline Project level status & Conceptual & $\begin{array}{c}\text { Pre- } \\
\text { feasibility }\end{array}$ & Feasibility & $\begin{array}{c}\text { Design and } \\
\text { construction }\end{array}$ & \multicolumn{2}{c}{ Operation } \\
& Temporary & Permanent \\
\hline $\begin{array}{l}\text { Geotechnical level } \\
\text { status }\end{array}$ & Level 1 & Level 2 & Level 3 & Level 4 & Level 5 & Level 6 \\
\hline Rock mass TLDC (\%) & $>30$ & $40-65$ & $60-75$ & $70-80$ & $80-85$ & $>85$ \\
$\mathrm{E}_{\mathrm{r}}(\%)$ & $<70$ & $35-60$ & $25-40$ & $20-30$ & $15-20$ & $<15$ \\
\hline
\end{tabular}

\subsection{Target levels of data confidence for underground mining projects}

The target levels of data confidence proposed by Read and Stacey (2009) were established for large open pit projects. In this paper it is deemed important to distinguish two types of excavations for underground openings at the operation stage: temporary and permanent. It is arguably justifiable that a higher level of confidence should be reached for permanent excavation that will be accessible to mine personnel for a long period of time than for a temporary excavation only accessible to mine equipment for a short period of time. This distinction is also coherent with the work of Gill et al. (2003; 2005). Table 3 presents, for the rock mass properties (such as the ones investigated in this paper), the target levels of data confidence at the various project level statuses. 


\subsection{Numerical example}

The methodology developed to establish the level of data confidence based on the maximal relative error at $95 \%$ is used in this section on the results obtained for UCS tests on the AR/HS rock type at Mining Project Donaldson for the 2014 campaign to demonstrate the calculation procedure. This sample had a size $n=21$ (21 rock specimens) with a mean UCS $(\bar{X})$ of $107.82 \mathrm{MPa}$ and a standard deviation (s) of $65.12 \mathrm{MPa}$. At a $95 \%(\alpha=0.05)$ confidence interval with a degree of freedom $(v=n-1)$ of 20 , a confidence coefficient $(t \alpha / 2, v)$ of 2.09 is found for a bilateral student law. The maximal relative error at $95 \%\left(E_{r}\right)$ on the distribution mean is computed using Equation 4 in Section 2.2.

$$
\begin{aligned}
& E_{r}=\frac{2.09 \frac{65.12}{\sqrt{21}}}{107.82} \\
& E_{r}=27.50 \%
\end{aligned}
$$

Then the level of confidence is determined using equation (5) presented in section 3.1.

$$
\begin{gathered}
T L D C(\%)=100-100(0.2750) \\
T L D C(\%)=72.50 \%
\end{gathered}
$$

A TLDC for rock mass properties of $72.5 \%$ is thus calculated. According to Table 3, such a TLDC is representative of a geotechnical level of 4 . This level is adequate to allow the use of these data at the design and construction stages of an underground mining project $(70 \%<\operatorname{TLDC}<80 \%)$.

\section{$4 \quad$ Results}

This section presents the results obtained for indirect tension and UCS tests on intact rock for the 2014 and 2015 campaigns at Mining Project Donaldson and Mining Project 14.

\subsection{Mining Project Donaldson}

At Mining Project Donaldson four rock types were tested. The following sections present the results for tensile strength and UCS tests. For all tests, the size of the sample $(n)$, the mean value $(\bar{X})$, the standard deviation (s), the coefficient of variation (CV), the TLDC and the geotechnical level (GL) reached are presented for each rock type.

\subsubsection{Tensile strength}

Table 4 shows the results for the 2014 campaign for tensile strength at Mining Project Donaldson. The sample size is smaller than the number suggested by ISRM. The CV is below $35 \%$, which is deemed acceptable by Bewick et al. (2015) among others. According to Read and Stacey (2009), a CV of about $10 \%$ is considered low and values greater than $30 \%$ are high. All CVs are considered as moderate since they range between 10 and 30\%. The GLs reached are between 2 and 4 showing that the level reached is acceptable for the actual stage of the project, but more information is clearly needed before starting the design and construction stage.

Table 5 presents the results for the 2015 campaign for tensile strength at Mining Project Donaldson. For three out of four of the rock types, the number of specimens tested is smaller than the ISRM suggested methods. All CVs are below 30\%. The GL reached is between 4 and 6 for all units. For OP, a GL of 6 is reached, which is sufficient for permanent excavations at the operational stage, according to Table 3 . It is the only rock type where the sample size is higher than the suggested ISRM guidelines. For 3/4 of the rock units, the GL reached is higher than the 2014 campaign. 
Table 4 Tensile strength results for the 2014 campaign at Mining Project Donaldson

\begin{tabular}{ccccccc}
\hline & \multicolumn{7}{c}{ Tensile strength $\left(\sigma_{t}\right)$} \\
Rock type & $\mathbf{n}$ & $\bar{X}(\mathbf{M P a})$ & $\mathbf{s}(\mathbf{M P a})$ & $\mathbf{C V}(\mathrm{MPa})$ & TLDC (\%) & $\mathbf{G L}$ \\
\hline OP & 5 & 20.99 & 5.56 & 26.47 & 67.13 & 3 \\
NG/L & 5 & 19.71 & 5.37 & 27.25 & 66.16 & 3 \\
AR/HS & 6 & 19.60 & 5.44 & 27.78 & 70.84 & 4 \\
AB & 4 & 12.82 & 3.71 & 28.94 & 53.95 & 2 \\
\hline
\end{tabular}

Table 5 Tensile strength results for the 2015 campaign at Mining Project Donaldson

\begin{tabular}{ccccccc}
\hline & \multicolumn{7}{c}{ Tensile strength $\left(\sigma_{t}\right)$} \\
Rock type & $\mathbf{n}$ & $\bar{X}(\mathbf{M P a})$ & $\mathbf{s}(\mathrm{MPa})$ & $\mathbf{C V}(\mathrm{MPa})$ & TLDC (\%) & GL \\
\hline OP & 12 & 18.08 & 3.84 & 21.22 & 86.52 & 6 \\
NG/L & 5 & 18.56 & 4.45 & 23.97 & 70.24 & 4 \\
AR/HS & 6 & 20.42 & 5.80 & 28.41 & 70.19 & 4 \\
AB & 4 & 19.38 & 3.44 & 17.74 & 71.78 & 4 \\
\hline
\end{tabular}

Table 6 Combined tensile results for the 2014 and 2015 campaigns at Mining Project Donaldson

\begin{tabular}{ccccccc}
\hline \multicolumn{7}{c}{ Tensile strength $\left(\boldsymbol{\sigma}_{\mathrm{t}}\right)$} \\
Rock type & $\mathbf{n}$ & $\overline{\boldsymbol{X}}(\mathrm{MPa})$ & $\mathbf{s}(\mathrm{MPa})$ & $\mathbf{C V}(\mathrm{MPa})$ & TLDC (\%) & $\mathbf{G L}$ \\
\hline OP & 17 & 18.94 & 4.44 & 23.44 & 87.95 & 6 \\
NG/L & 10 & 19.13 & 4.69 & 24.50 & 82.47 & 5 \\
AR/HS & 12 & 20.01 & 5.38 & 26.89 & 82.91 & 5 \\
AB & 8 & 16.10 & 4.82 & 29.95 & 74.96 & 4 \\
\hline
\end{tabular}

Table 6 presents the combined results of both campaigns. Combining the results allows meeting the requested number of tested specimens for $3 / 4$ of the units. The GL is 5 or 6 for three of the rock units. The GL reached is always superior to the one reached for the 2014 campaign. For 2 rock units, the GL is higher than the one obtained for the 2015 campaign. For the remaining two units, it is equal. Combining the results is clearly beneficial towards better defining the tensile strength at Mining Project Donaldson. The coefficients of variation are similar for individual and grouped campaigns. The obtained CVs suggest that, according to Bewick et al. (2015), the distribution is unimodal.

Figure 4 presents the histograms of tensile strength results at Mining Project Donaldson for both campaigns. Analysis of the histogram confirms both the unimodal nature of the distributions and the fact that both campaigns were beneficial in better defining tensile strength. 

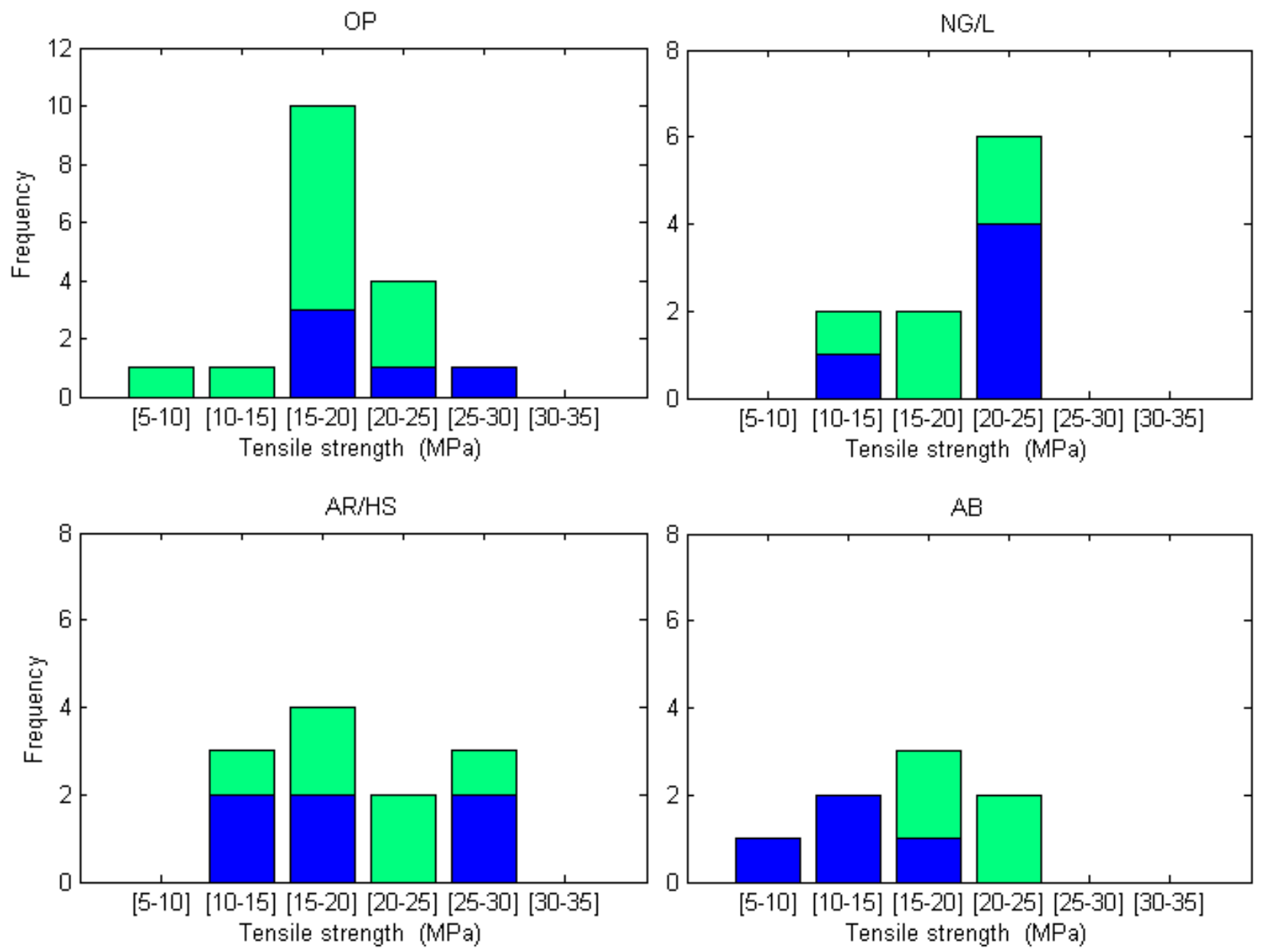

Figure 4 Histogram of tensile strength results for the 2014 (black) and 2015 (grey) campaigns at Mining Project Donaldson

\subsubsection{Uniaxial compressive strength}

Table 7 shows the UCS results for the 2014 campaign at Mining Project Donaldson. The sample size is larger than the number suggested by ISRM. The coefficient of variation is below $35 \%$ for $3 / 4$ of the units, which is deemed acceptable by Bewick at al. (2015). According to Read and Stacey (2009), CVs of about $10 \%$ are considered low and values greater than $30 \%$ are high. The CV is thus high for half of the units. The GLs reached are between 2 and 5, showing that the level reached is acceptable for the actual stage of the project for $3 / 4$ units, but more information is clearly needed before starting the design and construction stage.

Table 8 presents the results for the 2015 campaign for UCS at Mining Project Donaldson. For 2/4 rock types the number of specimens tested is smaller than the ISRM suggested methods. Three CVs are above $30 \%$, which is considered high. For OP, a GL of 6 is reached, which is sufficient at operation stage for permanent excavations. For half of the rock units, the GL reached is higher for that campaign.

Table 9 presents the combined results of both campaigns. Combining the results allows meeting the requested number of tested specimens for all units. The GLs for the combined analyses are never above the maximal value obtained for a single campaign. Combining the results is not beneficial towards better defining the UCS at Mining Project Donaldson.

The coefficients of variation are much smaller for individual campaigns than for grouped analysis. Figure 5 presents the histograms of UCS results at Mining Project Donaldson for both campaigns. Analysis of the histogram indicates a non-unimodal nature of the distributions. This suggests that UCS is varying within the same rock unit at Mining Project Donaldson. It is not advisable to group the data of these two campaigns 
for UCS results. One possible explanation for these differences is that drilling orientation differs between the two campaigns, the first campaign being drilled parallel to the main foliation, and the second one being drilled more perpendicular. This could explain why the 2014 results are lower than the 2015 . However, a similar trend arguably would have been observed for tensile strength, which is not the case. Furthermore, all failures along pre-existing geological weaknesses were rejected and thus not analysed.

Table 7 UCS results for the 2014 campaign at Mining Project Donaldson

\begin{tabular}{ccccccc}
\hline \multicolumn{7}{c}{ Uniaxial compressive strength $\left(\sigma_{\mathbf{c}}\right)$} \\
Rock type & $\mathbf{n}$ & $\overline{\boldsymbol{X}}(\mathrm{MPa})$ & $\mathbf{s}(\mathrm{MPa})$ & $\mathbf{C V}(\mathrm{MPa})$ & TLDC $(\%)$ & $\mathbf{G L}$ \\
\hline OP & 5 & 152.54 & 38.00 & 24.91 & 69.07 & 3 \\
NG/L & 10 & 117.20 & 25.66 & 21.89 & 84.34 & 5 \\
$\mathrm{AR} / \mathrm{HS}$ & 21 & 107.82 & 65.13 & 60.40 & 72.50 & 4 \\
$\mathrm{AB}$ & 5 & 54.85 & 19.13 & 34.88 & 56.69 & 2 \\
\hline
\end{tabular}

Table 8 UCS results for the 2015 campaign at Mining Project Donaldson

\begin{tabular}{ccccccc}
\hline \multicolumn{7}{c}{ Uniaxial compressive strength $\left(\boldsymbol{\sigma}_{\mathbf{c}}\right)$} \\
Rock type & $\mathbf{n}$ & $\overline{\boldsymbol{X}}(\mathbf{M P a})$ & $\mathbf{s}(\mathrm{MPa})$ & $\mathbf{C V}(\mathbf{M P a})$ & TLDC (\%) & $\mathbf{G L}$ \\
\hline OP & 6 & 233.13 & 30.94 & 13.27 & 86.07 & 6 \\
NG/L & 6 & 264.20 & 62.06 & 23.49 & 75.35 & 4 \\
AR/HS & 3 & 268.00 & 63.89 & 23.84 & 40.78 & 2 \\
AB & 3 & 239.60 & 72.50 & 30.26 & 24.83 & N/D \\
\hline
\end{tabular}

Table 9 Combined UCS results for the 2014 and 2015 campaigns at Mining Project Donaldson

\begin{tabular}{ccccccc}
\hline \multicolumn{7}{c}{ Uniaxial compressive strength $\left(\sigma_{\mathbf{c}}\right)$} \\
Rock type & $\mathbf{n}$ & $\overline{\boldsymbol{X}}(\mathrm{MPa})$ & $\mathbf{s}(\mathrm{MPa})$ & $\mathbf{C V}(\mathrm{MPa})$ & TLDC (\%) & $\mathbf{G L}$ \\
\hline OP & 11 & 196.50 & 53.18 & 27.06 & 81.82 & 5 \\
NG/L & 16 & 172.32 & 84.15 & 48.83 & 73.98 & 4 \\
AR/HS & 24 & 127.85 & 83.50 & 65.31 & 72.42 & 4 \\
AB & 8 & 124.13 & 104.18 & 83.93 & 29.83 & N/D \\
\hline
\end{tabular}



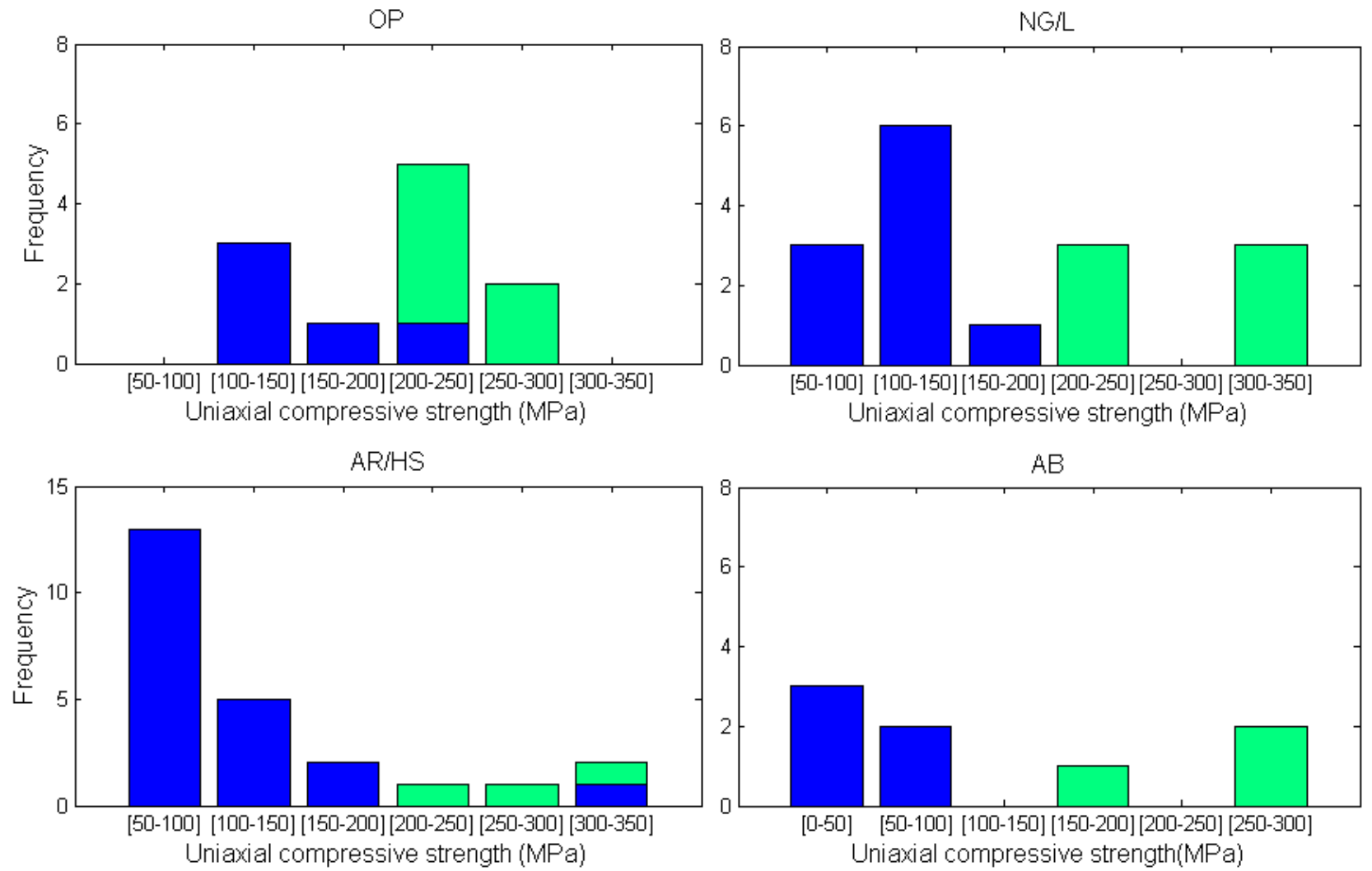

Figure 5 Histogram of UCS for the 2014 (black) 2015 (grey) campaigns at Mining Project Donaldson

\subsection{Mining Project 14}

At Mining Project 14 four rock types were also tested. The following sections present the results for tensile strength and UCS tests. For all tests, the size of the sample $(n)$, the mean value $(X)$, the standard deviation (s), the CV, the TLDC and the GL reached are presented.

\subsubsection{Tensile strength}

Table 10 shows the results for the 2014 campaign for tensile strength at Mining Project 14 . The sample size is smaller than the number suggested by ISRM. The CV is below $35 \%$ which is deemed acceptable by Bewick et al. (2015), among others. According to Read and Stacey (2009), the three CVs are considered low since they are smaller than $10 \%$. The GL reached are between 2 and 6 , showing that the level reached is acceptable for the actual stage of the project, but more information is clearly needed for two units before starting the design and construction stages (GL 4). On the other hand two units are already at a GL of 6 (OP and PE).

Table 11 presents the results for the 2015 campaign for tensile strength at mining Project 14 . For $3 / 4$ of the rock types, the number of specimens tested is smaller than the ISRM suggested methods. All CVs are below $35 \%$. For NG/L, a GL of 6 is reached, which is sufficient for permanent excavations at the operational stage according to Table 2 . It is also the only rock unit where the GL reached is higher than the 2014 campaign.

Table 12 presents the combined results of both campaigns. Combining the results allows meeting the requested number of tested specimens for $3 / 4$ of the units. The GL is 6 for 3 of the rock units again indicating zero additional rock testing is required for these units. The GL reached is superior or equal to the one reached for the 2014 or 2015 campaign for three units. For PE, GL is between the results obtained at both campaigns. 
Figure 6 presents the histograms of tensile strength results at Mining Project 14 for both campaigns. Analysis of the histogram confirms both the unimodal nature of the distributions and the fact that both campaigns were beneficial in better defining tensile strength for OP, OP-OZ and NG-L. For PE, it appears that the results vary within the investigated area in Mining Project 14. The results from the 2014 campaign are characterised by higher values.

Table 10 Tensile strength results for the 2014 campaign at Mining Project 14

\begin{tabular}{ccccccc}
\hline & \multicolumn{7}{c}{ Tensile strength $\left(\sigma_{\mathrm{t}}\right)$} \\
Rock type & $\mathbf{n}$ & $\overline{\boldsymbol{X}}(\mathbf{M P a})$ & $\mathbf{s}(\mathrm{MPa})$ & $\mathbf{C V}(\mathrm{MPa})$ & TLDC (\%) & GL \\
\hline OP & 7 & 21.19 & 2.29 & 10.81 & 90.00 & 6 \\
OP-OZ & 2 & 21.52 & 1.06 & 4.93 & 55.72 & 2 \\
NG/L & 7 & 21.49 & 5.53 & 25.74 & 76.20 & 4 \\
PE & 7 & 27.92 & 2.62 & 9.39 & 91.31 & 6 \\
\hline
\end{tabular}

Table 11 Tensile strength results for the 2015 campaign at Mining Project 14

\begin{tabular}{|c|c|c|c|c|c|c|}
\hline \multicolumn{7}{|c|}{ Tensile strength $\left(\sigma_{t}\right)$} \\
\hline Rock type & $n$ & $\bar{X}(\mathrm{MPa})$ & $\mathrm{s}(\mathrm{MPa})$ & $\mathrm{CV}(\mathrm{MPa})$ & TLDC (\%) & GL \\
\hline $\mathrm{OP}$ & 8 & 20.99 & 4.45 & 21.22 & 82.26 & 5 \\
\hline OP-OZ & 2 & 24.00 & 2.12 & 8.84 & 20.59 & $\mathrm{~N} / \mathrm{D}$ \\
\hline$N G / L$ & 17 & 19.10 & 3.64 & 19.07 & 90.20 & 6 \\
\hline PE & 5 & 15.80 & 5.15 & 32.58 & 59.55 & 2 \\
\hline
\end{tabular}

Table 12 Combined results for the 2014 and 2015 campaigns at Mining Project 14

\begin{tabular}{ccccccc}
\hline & \multicolumn{7}{c}{ Tensile strength $\left(\sigma_{t}\right)$} \\
Rock type & $\mathbf{n}$ & $\overline{\boldsymbol{X}}(\mathrm{MPa})$ & $\mathbf{s}(\mathrm{MPa})$ & $\mathbf{C V}(\mathrm{MPa})$ & TLDC (\%) & $\mathbf{G L}$ \\
\hline OP & 15 & 21.08 & 3.49 & 16.55 & 90.84 & 6 \\
OP-OZ & 4 & 22.76 & 1.98 & 8.70 & 86.15 & 6 \\
NG/L & 24 & 19.80 & 4.29 & 21.69 & 90.84 & 6 \\
PE & 12 & 22.87 & 7.23 & 31.63 & 79.90 & 4 \\
\hline
\end{tabular}

\subsubsection{Uniaxial compressive strength}

Table 13 shows the results for the 2014 campaign for UCS at Mining Project 14 . The sample size is larger than the number suggested by ISRM for $3 / 4$ of the units. The coefficient of variation is below $35 \%$ for all units, which is deemed acceptable by Bewick at al. (2015). The GLs reached are between 5 and 6 for OP, $\mathrm{NG} / \mathrm{L}$ and $\mathrm{PE}$, showing that the level reached is acceptable for the actual stage of the project, but more information is needed before starting the design and construction stage for OP-OZ. 

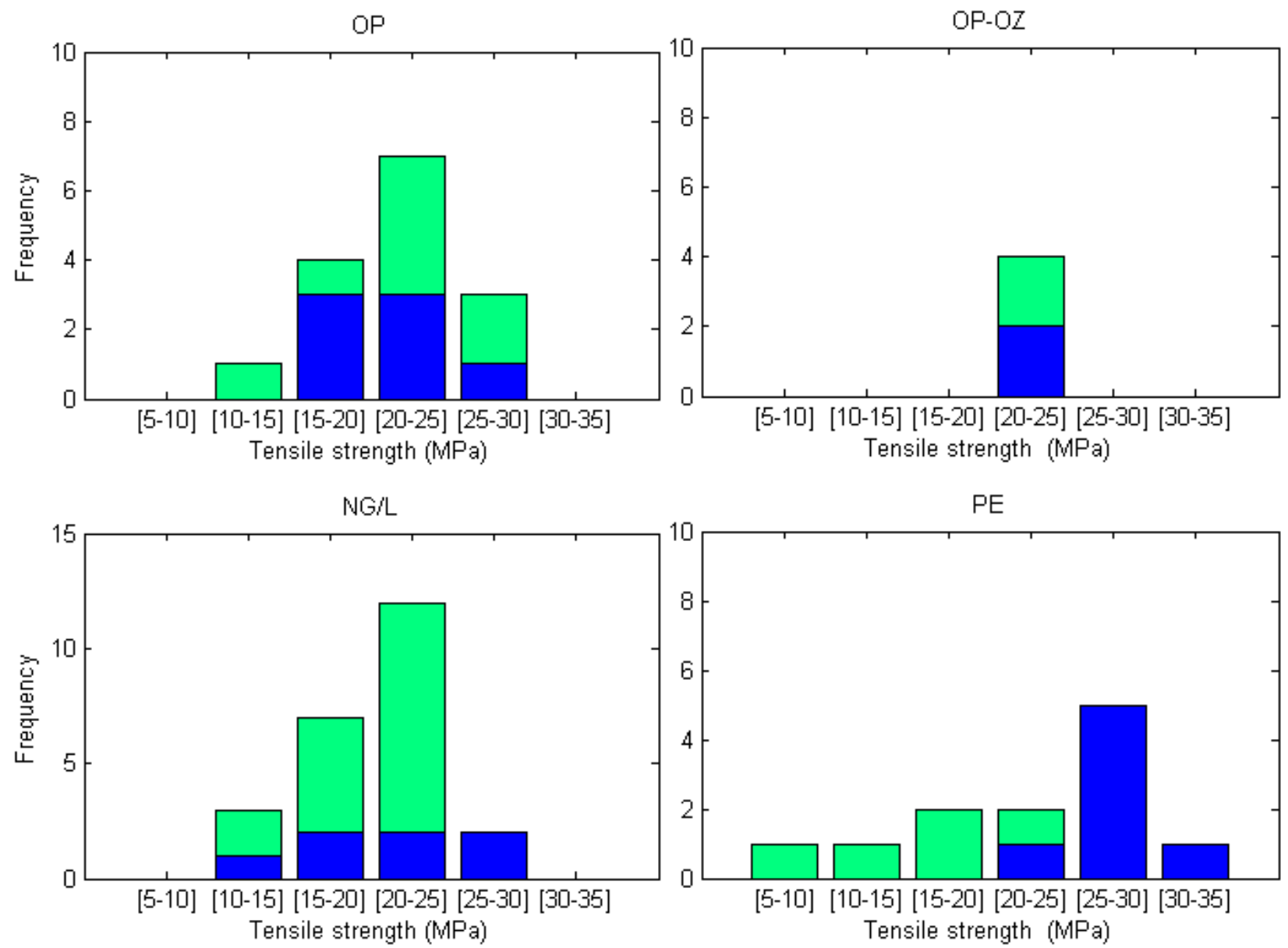

Figure 6 Histogram of tensile strength results for the 2014 (black) 2015 (grey) campaigns at Mining Project 14

Table 14 presents the results for the 2015 campaign for UCS at Mining Project 14 . For OP-OZ the number of specimens tested is smaller than the ISRM suggested methods. All CVs are below $25 \%$, which is considered acceptable by Bewick at al. (2015) and Read and Stacey (2009). A GL of 6 is reached for NG/L and PE, which is sufficient at the operational stage for permanent excavations. For two out of four rock units, the $\mathrm{GL}$ reached is higher for that campaign. For OP, a GL of 4 is reached. For OP-OZ the available data does not allow the evaluation of a GL.

Table 15 presents the combined results of both campaigns. Combining the results allows meeting the requested number of tested specimens for all units except OP-OZ. The GL, for the combined analyses, are equal to the highest value of both campaigns (GL of 6) for NG/L and PE. For OP it is equal to the lowest value of both campaigns (4). For OP-OZ it enables the evaluation of a GL reaching a value of 2, which was not possible for any of the 2 campaigns. It can also be seen that neither the number of specimens nor the $\mathrm{CV}$ s are directly correlated to the GL obtained.

The coefficients of variation are similar for individual campaigns and grouped analysis except for OP. Figure 7 presents the histograms of UCS results at Mining Project 14 for both campaigns. Analysis of the histogram indicates the unimodal nature of the distributions for the PE and NG/L units, thus confirming that both campaigns were beneficial in better defining UCS. For OP it suggests that UCS varies within Mining Project 14. Higher values are obtained for the 2015 campaigns. It is not advisable to group the data of these two campaigns. Drilling for both campaigns was done with similar orientations. 
Table 13 UCS results for the 2014 campaign at Mining Project 14

\begin{tabular}{ccccccc}
\hline \multicolumn{7}{c}{ Uniaxial compressive strength $\left(\sigma_{\mathbf{c}}\right)$} \\
Rock type & $\mathbf{n}$ & $\bar{X}(\mathbf{M P a})$ & $\mathbf{s}(\mathbf{M P a})$ & $\mathbf{C V}(\mathbf{M P a})$ & TLDC (\%) & GL \\
\hline OP & 7 & 169.60 & 26.48 & 15.61 & 85.56 & 6 \\
OP-OZ & 3 & 239.72 & 82.51 & 34.42 & 14.49 & N/D \\
NG/L & 10 & 204.49 & 65.15 & 31.86 & 77.21 & 4 \\
PE & 15 & 271.78 & 72.81 & 26.79 & 85.17 & 6 \\
\hline
\end{tabular}

Table 14 UCS results for the 2015 campaign at Mining Project 14

\begin{tabular}{ccccccc}
\hline & \multicolumn{7}{c}{ Uniaxial compressive strength $\left(\sigma_{\mathbf{c}}\right)$} \\
Rock type & $\mathbf{n}$ & $\overline{\boldsymbol{X}}(\mathbf{M P a})$ & $\mathbf{s}(\mathrm{MPa})$ & $\mathbf{C V}(\mathrm{MPa})$ & TLDC (\%) & $\mathbf{G L}$ \\
\hline OP & 4 & 298.60 & 43.84 & 14.68 & 76.64 & 4 \\
OP-OZ & 1 & 367.60 & N/D & N/D & N/D & N/D \\
NG/L & 17 & 229.40 & 52.40 & 22.84 & 88.25 & 6 \\
PE & 7 & 374.33 & 46.44 & 12.41 & 88.53 & 6 \\
\hline
\end{tabular}

Table 15 Combined UCS results for the 2014 and 2015 campaigns at Mining Project 14

\begin{tabular}{ccccccc}
\hline \multicolumn{7}{c}{ Uniaxial compressive strength $\left(\sigma_{\mathbf{c}}\right)$} \\
Rock type & $\mathbf{n}$ & $\overline{\boldsymbol{X}}(\mathrm{MPa})$ & $\boldsymbol{s}(\mathrm{MPa})$ & $\mathbf{C V}(\mathrm{MPa})$ & TLDC (\%) & $\mathbf{G L}$ \\
\hline OP & 11 & 216.51 & 72.34 & 33.41 & 77.55 & 4 \\
OP-OZ & 4 & 271.69 & 92.88 & 34.19 & 45.60 & 2 \\
NG/L & 27 & 220.17 & 57.53 & 26.13 & 89.66 & 6 \\
PE & 22 & 304.41 & 80.87 & 26.57 & 88.22 & 6 \\
\hline
\end{tabular}

\section{Discussion}

The results of the first campaign were used to assess target DDH for intact rock characterisation for the second campaign. Nonetheless, practical site-specific considerations will always influence the number and timing of tests to be performed. For example, at Raglan Mine, a limited number of excavations are mined through geological units $A B$ and $N G / L$, thus diminishing the need to improve the confidence in these specific rock types. In contrast, many drifts are excavated in the PE geological unit, thus increasing the need to improve our confidence in this unit. Furthermore, the availability of rock specimens from the $\mathrm{OZ}$ is also limited and/or difficult since laboratory assays are prioritised. Nevertheless, for critical rock units the goal is always to improve confidence in the rock properties as the mine progresses through the project stages into operation.

It was shown that the number of strength tests is not always a sufficient criterion on which to base our confidence for a rock mass property. This comment is also valid for the CV. Similar CV values may lead to different values in geotechnical levels. The methodology presented can be useful by showing that fewer tests are needed at the early stages of a mining project when by default the definition of the orebody is crude and drilling resources limited. It can also be beneficial in selecting drill targets and it provides a structured repeatable method for presenting quantitative information on the confidence level for material strength. 

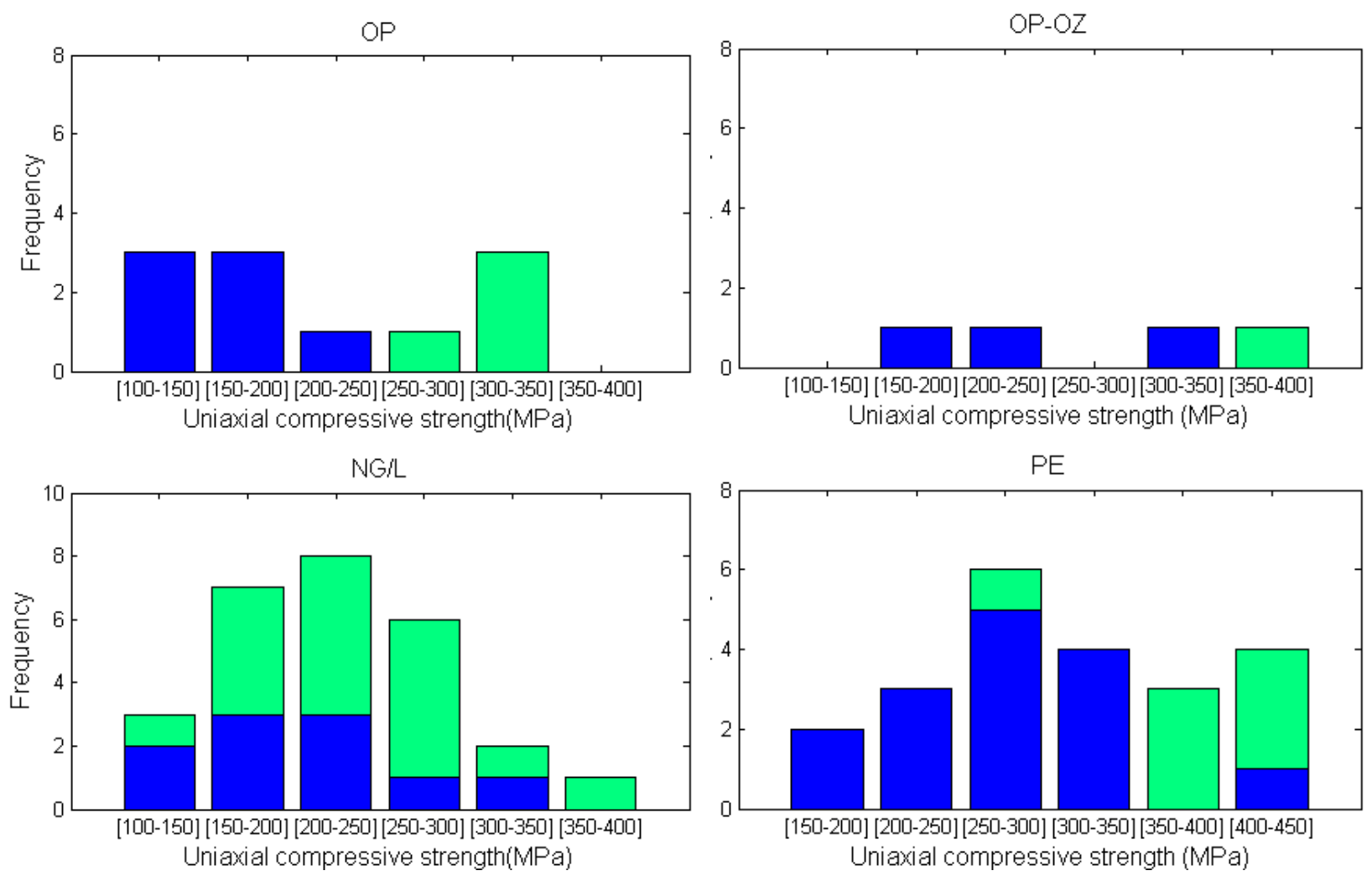

Figure 7 Histogram of UCS for the 2014 (black) 2015 (grey) campaigns at Mining Project 14

At Mining Project Donaldson the drill program was limited for the first campaign, but an improved coverage of the target zone was achieved by the second drill campaign. The results indicate that tensile strength is similar over the entire mining area and that no additional index testing should be performed; however, UCS varies significantly over the zone and additional testing for critical rock units are warranted.

At Mining Project 14 the drill holes for both campaigns are located within a relatively limited radius of $100 \mathrm{~m}$. Nonetheless, test specimens were recovered from various depths, and an agreement at varying depths and sufficient geotechnical levels for tensile strengths was achieved. The same comment is valid for UCS results for the NG/L and PE geological units. However, additional UCS testing could be envisaged for critical units close to other mineralised area within Mining Project 14.

\section{Conclusion}

At the early stages of an underground mining project in the Canadian arctic, two successive field and laboratory campaigns were undertaken to evaluate intact rock properties: tensile strength and UCS. All tests were performed according to the ISRM suggested methods. The obtained results were compared to target levels of confidence associated with different stages of a mining project. This was done using statistical analysis methods. Levels of confidence required for permanent versus temporary openings at underground mines have been proposed. The proposed methodology proved efficient in maximising the outcomes from the results obtained for an intact rock-property characterisation campaign and in providing insightful information for the planning of future campaigns.

\section{Acknowledgement}

The authors would like to acknowledge the financial support of Fonds nature et technologies. The authors would also like to thank Raglan Mine, a Glencore company, for providing geotechnical data. 


\section{References}

Bewick, RP, Amann, F \& Kaiser, PK 2015, 'Interpretation of UCS test results for engineering design', Proceedings of the 13th International Congress of Rock Mechanics Montreal, Canada.

Brown, ET (ed.) 1981, Rock characterization, testing \& monitoring - ISRM suggested methods, Pergamon Press, Oxford.

Fillion, MH, Hadjigeorgiou, J 2013, 'Reliability of strength estimates based on limited laboratory data', in P Dight (ed.), Proceedings of the 2013 International Symposium on Slope Stability in Open Pit Mining and Civil Engineering (Slope Stability 2013), Australian Centre for Geomechanics, Perth, pp. 163-176.

Gill, DE, Corthésy, R \& Leite, MH 2003, Les valeurs pratiques des propriétés mécaniques des roches, report, no. EPM-RT-2003-05, École Polytechnique de montréal, Montreal, QC. [In French]

Gill, DE, Corthésy, R \& Leite, MH 2005, 'Determining the minimal number of specimens for laboratory testing of rock properties', Engineering Geology, vol. 78, no. 1-2, pp. 29-51.

Joint Ore Reserves Committee 2004, JORC Code: Australasian Code for Reporting of Exploration Results, Mineral Resources and Ore Reserves, Joint Ore Reserves Committee, South Carlton.

Montgomery, DC \& Runger, GC 2011, Applied Statistics and Probability for Engineers, 5th edn, John Wiley \& Sons, Inc., Hoboken, NJ.

Read, J 2013, 'Data gathering, interpretation, reliability and geotechnical models', in P Dight (ed.), Proceedings of the 2013 International Symposium on Slope Stability in Open Pit Mining and Civil Engineering (Slope Stability 2013), Australian Centre for Geomechanics, Perth, pp. 949-962.

Read, J \& Stacey, P 2009, Guidelines for open pit slope design, CRC Press, Boca Raton, FL. 